\title{
IONS IN GRAIN MANTLES: A NEW EXPLANATION FOR THE 6.86 MICRON ABSORPTION
} IN W33A

\author{
RuUd Grim, J. Mayo Greenberg, Willem Schutte, and Bernard Schmitt \\ Laboratory Astrophysics, University of Leiden \\ Received 1987 August 10; accepted 1989 March 29
}

\begin{abstract}
We have investigated the $6.86 \mu \mathrm{m}$ absorption in W33A using the results of laboratory experiments simulating the photochemistry of interstellar grain mantles. The 5-8 $\mu \mathrm{m}$ IR spectrum, and particularly the $6.86 \mu \mathrm{m}$ absorption, of W33A can be reproduced with ultraviolet irradiated water-rich ices.

The 5-8 $\mu \mathrm{m}$ spectrum of W33A exhibits effects which are interpreted as due to dust material heated to different temperatures along the line of sight. Photolyzed dust mantles with a temperature less than $100 \mathrm{~K}$ provide the $6.0 \mu \mathrm{m}$ absorption, while dust mantles heated to $T>100 \mathrm{~K}$ are the main contributors to the 6.86 $\mu \mathrm{m}$ absorption feature.

Different photolysis and heating scenarios, as well as line of sight effects, are required to account for the 5-8 $\mu \mathrm{m}$ spectra of other protostellar objects.

Subject headings: infrared: spectra - interstellar: grains — interstellar: molecules — laboratory spectra line identifications
\end{abstract}

\section{INTRODUCTION}

The identification of the interstellar $4.62 \mu \mathrm{m}$ absorption as due to the ion $\mathrm{OCN}^{-}$(Grim and Greenberg 1987, hereafter GG87) and not to an isonitrile as suspected earlier (Larson et al. 1985) was made possible using laboratory-produced isotopic frequency shifts. In GG87 we suggested that, in addition to the $4.62 \mu \mathrm{m}$ absorption, other interstellar IR bands might also be due to ionic species in ice mantles. In many UVirradiated and heated ice mixtures containing $\mathrm{NH}_{3}$ there appeared a feature resembling the $6.86 \mu \mathrm{m}$ feature in W33A. Could this also be attributed to an ionic compound?

A wide range of assignments have been earlier put forward for the $6.86 \mu \mathrm{m}$ feature observed toward protostars (Russell, Soifer, and Puetter 1977; Soifer et al. 1979) and H II regions (Puetter et al. 1979, hereafter P79). Among them were hydrated silicates (P79; Hecht et al. 1986), carbonates (P79; Knacke and Krätschmer 1980; Sandford and Walker 1985) and the methyl $\left(-\mathrm{CH}_{3}\right)$ and methylene $\left(-\mathrm{CH}_{2}\right)$ bending vibration in hydrocarbons (P79; Soifer et al. 1979; d'Hendecourt et al. 1986, hereafter dH86) or in alcohols (Tielens et al. 1984; Tielens and Allamandola 1987).

The hydrocarbon bending explanation requires a stronger $3.4 \mu \mathrm{m}$ absorption than observed. To avoid this dilemma, Tielens et al. (1984) stated that such simple alcohols as methanol $\left(\mathrm{CH}_{3} \mathrm{OH}\right)$ generally show a reduced $3.4 \mu \mathrm{m}$ band with respect to the $6.86 \mu \mathrm{m}$ band. The observed $3.53 \mu \mathrm{m}$ feature in W33A (Bass et al. 1988), if due to methanol, implies a $6.86 \mu \mathrm{m}$ feature which is 10 times lower than observed when one compares with laboratory mixtures containing methanol (Baas et al. 1988; Grim et al. 1989a, hereafter G89a).

UV irradiation of ice mixtures (not containing $\mathrm{CH}_{3} \mathrm{OH}$ ) also provided a suggestive, but not initially precise, match with the interstellar $6.86 \mu \mathrm{m}$ absorption (Tielens et al. 1984; dH86). In the irradiated samples $\mathrm{CH}_{3} \mathrm{OH}$ was not detected so that the $6.86 \mu \mathrm{m}$ band was then tentatively attributed to aliphatic $\left(-\mathrm{CH}_{2},-\mathrm{CH}_{3}\right)$ hydrocarbons adjacent to an unsaturated group (e.g., $\mathrm{C}=0$ ) needed to explain the absence of an absorption feature at $3.4 \mu \mathrm{m}$ (dH86). The fact that the $6.86 \mu \mathrm{m}$ absorp- tion is present at most weakly or not at all in an irradiated $\mathrm{H}_{2} \mathrm{O} / \mathrm{CO}$ or $\mathrm{H}_{2} \mathrm{O} / \mathrm{CH}_{4}$ ice (Schutte 1988), appears to be inconsistent with the aliphatic hydrocarbon explanation.

These inconsistencies and the latest results on the formation of ions in dirty ices (Grim et al. 1989b, hereafter G89b) provided an incentive to reinvestigate the assignment of the $6.86 \mu \mathrm{m}$ absorption. In this Letter we discuss specifically the astrophysical relevance of one absorption near $6.86 \mu \mathrm{m}$ that appeared in the laboratory spectra of photolyzed samples containing $\mathrm{NH}_{3}$ with or without carbon-bearing molecules. Detailed arguments for assigning this particular band to $\mathrm{NH}_{4}{ }^{+}$are given in $\mathrm{G} 89 \mathrm{~b}$. In any case, whether the assignment is justified or not, the band position and profile of the laboratory $6.86 \mu \mathrm{m}$ band matches that of $W 33 A$ very well.

\section{EXPERIMENTAL RESULTS AND DISCUSSION}

\section{a) A Simple Nonvolatile Nitrogen-bearing 6.86 Micron Carrier}

Figure $1 a$ shows the 5-8 $\mu \mathrm{m}$ IR spectra of some photolyzed and annealed laboratory samples. At $12 \mathrm{~K}$ we see that an absorption at $6.68 \mu \mathrm{m}\left(1497 \mathrm{~cm}^{-1}\right)$ is preferentially made in samples containing $\mathrm{NH}_{3}$ from which we concluded that the laboratory band carrier does not contain carbon atoms (G89b). Heating of samples with this absorption band leads to a wavelength shift that depends on the composition and temperature of the irradiated sample. In water-rich astrophysically relevant ice mixtures, the band shifts to $6.88 \mu \mathrm{m}\left(1454 \mathrm{~cm}^{-1}\right)$ at $176 \mathrm{~K}$, a temperature that is high enough to sublimate all $\mathrm{H}_{2} \mathrm{O}$ on a time scale of a few hours. During the $\mathrm{H}_{2} \mathrm{O}$ sublimation at 176 $\mathrm{K}$, the band position is not further affected. When heating to $196 \mathrm{~K}$ or higher, the wavelength is raised finally to $6.91 \mu \mathrm{m}$ $\left(1447 \mathrm{~cm}^{-1}\right)$.

After irradiation of the $\mathrm{H}_{2} \mathrm{O} / \mathrm{NH}_{3} / \mathrm{CO} / \mathrm{O}_{2}=10 / 1 / 1 / 1$ mixture at $12 \mathrm{~K}$, not only does the $6.68 \mu \mathrm{m}$ absorption appear, but also a broadening at both sides of the $6.0 \mu \mathrm{m}$ band is observed (Fig. $1 b$ ). The broadening at the long-wavelength side is due to an absorption at $6.31 \mu \mathrm{m}\left(1584 \mathrm{~cm}^{-1}\right)$ which becomes clearly delineated after heating to $100 \mathrm{~K}$. The broadening at 


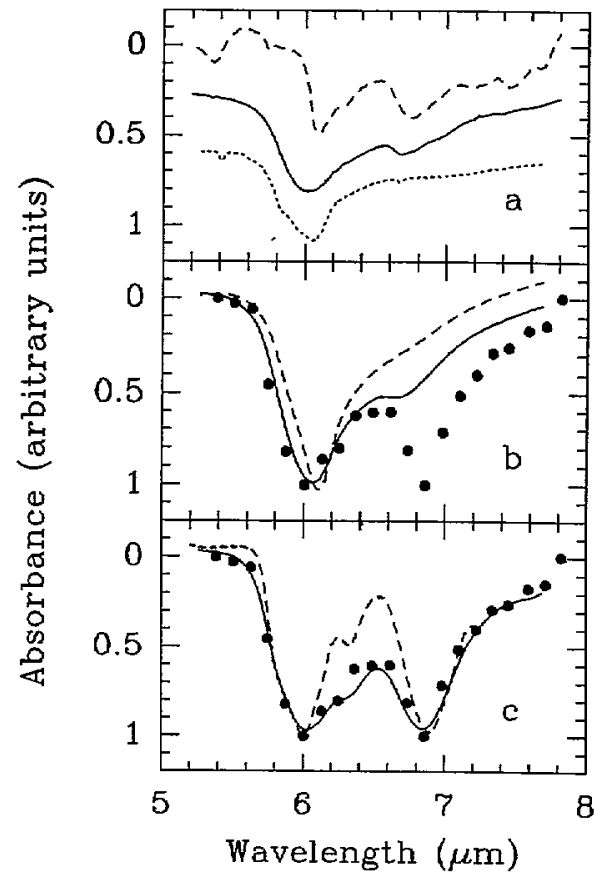

FIG. 1.-(a) IR absorption spectra at 5-8 $\mu \mathrm{m}$ of three laboratory samples: (i) (dashed line) $\mathrm{NH}_{3} / \mathrm{O}_{2}=1 / 1$ after $4 \mathrm{hr} \mathrm{UV}$ and heating to $120 \mathrm{~K}$. Note the appearance of the nitrogen carrying " $6.86 \mu \mathrm{m}$ " absorber; (ii) (solid line) the astrophysical mixture $\mathrm{H}_{2} \mathrm{O} / \mathrm{NH}_{3} / \mathrm{CO} / \mathrm{O}_{2}=10 / 1 / 1 / 1$ after $2 \mathrm{hr}$ simultaneous irradiation and deposition at $12 \mathrm{~K}$; (iii) (dotted line) $\mathrm{H}_{2} \mathrm{O} / \mathrm{CO}=5 / 2$ after UV irradiation. Note that there is no " $6.86 \mu \mathrm{m}$ " absorption (from Schutte 1988). Intensity scales are arbitrary. The resolution is $4 \mathrm{~cm}^{-1}$. (b) Laboratory comparisons with the observed 5-8 $\mu \mathrm{m}$ spectrum of W33A (Tielens and Allamandola 1987): (i) (dashed line) The spectrum of condensed $\mathrm{H}_{2} \mathrm{O} / \mathrm{CO} / \mathrm{NH}_{3}=4 / 2 / 1$ at $12 \mathrm{~K}$. Note that the $6.0 \mu \mathrm{m}$ band cannot be reproduced with nonirradiated ices. (ii) (solid line) The spectrum of the astrophysical mixture $\mathrm{H}_{2} \mathrm{O} / \mathrm{NH}_{3} / \mathrm{CO} / \mathrm{O}_{2}=10 / 1 / 1 / 1$ after $2 \mathrm{hr}$ simultaneous irradiation and deposition at $12 \mathrm{~K}$. Note the $6.0 \mu \mathrm{m}$ band match. All laboratory spectra are smoothed to $30 \mathrm{~cm}^{-1}$ resolution comparable with the resolution of the W33A data $(\lambda / \Delta \lambda \sim 50)$. (c) (i) (solid line) The irradiated astrophysical ice mixture $\mathrm{H}_{2} \mathrm{O} / \mathrm{NH}_{3} / \mathrm{CO} / \mathrm{O}_{2}=10 / 1 / 1 / 1$ immediately after heating to $176 \mathrm{~K}$ at $30 \mathrm{~cm}^{-1}$ resolution compared with the spectrum of W33A. (ii) (dashed line) A composite spectrum at $4 \mathrm{~cm}^{-1}$ resolution of $12 \mathrm{~K}$ and $176 \mathrm{~K}$ IR spectra (for details see text and Fig. 2). Note the almost dramatic effect of low resolution. The $6.3 \mu \mathrm{m}$ absorption seen in (ii) at $4 \mathrm{~cm}^{-1}$ resolution has almost blended out in (i) at 30 $\mathrm{cm}^{-1}$ resolution.

the short-wavelength side is due to an absorption peaking at $6.0 \mu \mathrm{m}\left(1670 \mathrm{~cm}^{-1}\right)$ after $\mathrm{H}_{2} \mathrm{O}$ sublimation.

Identifications of these laboratory bands are given in $\mathrm{G} 89 \mathrm{~b}$ : the " $6.86 \mu \mathrm{m}$ " feature is assigned to $\mathrm{NH}_{4}{ }^{+}$and the $6.31 \mu \mathrm{m}$ band is attributed to $\mathrm{HCOO}^{-}$. The short wavelength broadening is explained by $\mathrm{HCONH}_{2}$. The chemical reaction pathways leading to ion formation are also discussed in $\mathbf{G} 89 b$. Furthermore, using the principles of nitrogen conservation and charge balance, an IR band strength for the $6.86 \mu \mathrm{m}$ absorption of $\mathrm{NH}_{4}{ }^{+}$of about $2 \times 10^{-16} \mathrm{~cm} \mathrm{molecule}{ }^{-1}$ is estimated (G89b). Note that this estimate is in fact independent of the proposed assignment as long as the carrier contains only one nitrogen atom.

\section{b) Reproduction of the 5-8 Micron Region of W33A with Irradiated Ices}

The interpretation of the IR data is not simple for deeply embedded objects because we observe differently irradiated and heated ice mantles along the line of sight. For example, in protostellar sources such as W33A and BN the grain mantle compositions vary depending on the distance from the source. The mantles close in are too hot to maintain ice mantles, while those farther out may exhibit varying degrees of annealing of ice (Greenberg 1982; van de Bult, Greenberg, and Whittet 1985). The case of W33A seems to exhibit heating of grains along the line of sight at least to the degree needed to evaporate most of the CO (Lacy et al. 1984; Geballe et al. 1985). Thus it is not surprising that the $12 \mathrm{~K}$ spectra of photolyzed ices reasonably fit the $6.0 \mu \mathrm{m}$ band but not the entire 5-8 $\mu \mathrm{m}$ spectrum (Fig. $1 b$; solid line).

In the laboratory, elevated temperatures were needed to shift the $6.68 \mu \mathrm{m}$ band to the appropriate interstellar position $(6.86$ $\mu \mathrm{m})$. The $30 \mathrm{~cm}^{-1}$ resolution spectrum taken immediately after reaching $176 \mathrm{~K}$ matches the entire $5-8 \mu \mathrm{m}$ spectrum of W33A (Fig. 1c, solid line). After complete $\mathrm{H}_{2} \mathrm{O}$ sublimation at $176 \mathrm{~K}$, the match of the $6.0 \mu \mathrm{m}$ is less satisfactory, while the $6.86 \mu \mathrm{m}$ band match is still maintained. With an appropriate combination of the $30 \mathrm{~cm}^{-1}$ resolution spectra taken at $12 \mathrm{~K}$ and $176 \mathrm{~K}$ (after $20 \mathrm{hr}$ annealing time) a good fit is achieved again. Note that in Figure $1 c$ the dashed line represents the $4 \mathrm{~cm}^{-1}$ resolution spectrum to demonstrate the effect of the resolution. This composite spectrum also provides a reasonable match of the W33A spectrum outside the $5-8 \mu \mathrm{m}$ region (Fig. 2). Such a match cannot be achieved with $176 \mathrm{~K}$ spectra alone.

A slight inconsistency with the interstellar wavelength seems to remain: in the laboratory heating from 176 to $196 \mathrm{~K}$ ultimately shifted the $\mathrm{NH}_{4}{ }^{+}$band from $6.88 \mu \mathrm{m}$ to $6.91 \mu \mathrm{m}$. This discrepancy is circumvented by using ices with less $\mathrm{H}_{2} \mathrm{O}$ and $\mathrm{O}_{2}$; for example, after UV irradiation and heating of an $\mathrm{H}_{2} \mathrm{O} / \mathrm{CO} / \mathrm{NH}_{3}=5 / 2 / 1$ mixture, the $\mathrm{NH}_{4}{ }^{+}$band remains at $6.86 \mu \mathrm{m}$ (Schutte 1988). However, in that experiment too much carbonyl absorption was observed to match the entire 5-8 $\mu \mathrm{m}$ spectrum of W33A. The band position of $\mathrm{NH}_{4}{ }^{+}$in irradiated ices requires further study in order to see under what precise conditions or rather, under what combination of conditions, it is observed at the interstellar position(s) (see $\S \mathrm{II} e$ ).

\section{c) Analysis of the 5-8 Micron Spectrum of W33A}

What information is contained in the $5-8 \mu \mathrm{m}$ spectral fingerprint region of W33A about the chemical composition and physical history of the ice mantles? First of all, the $6.0 \mu \mathrm{m}$ band is reasonably reproduced by a pure unprocessed $\mathrm{H}_{2} \mathrm{O}$ ice (Tielens and Allamandola 1987). However, as can be seen from Figure $1 b$, a nonirradiated ice containing $\mathrm{H}_{2} \mathrm{O}, \mathrm{CO}$, and $\mathrm{NH}_{3}$ does not provide a good fit of the $6.0 \mu \mathrm{m}$ band position and shape. The width of the $6.0 \mu \mathrm{m}$ absorption band in W33A is too large to be explained by such unprocessed ice mantles. The broadening upon UV irradiation at the short-wavelength side of this band has been attributed to the formation of such species as $\mathrm{H}_{2} \mathrm{CO}\left(5.7:^{\circ}-5.81 \mu \mathrm{m} ; 1740-1720 \mathrm{~cm}^{-1}\right)$ and $\mathrm{HCONH}_{2}\left(5.92-5.99 \mu \mathrm{m} ; 1690-1670 \mathrm{~cm}^{-1}\right)$ (dH86; Schutte 1988 ; G89b). The observed widening on the long-wavelength shoulder could be due to the $\mathrm{HCOO}^{-}$ion $(\mathrm{G} 89 \mathrm{~b})$.

If the interstellar $6.86 \mu \mathrm{m}$ band can be attributed to the single nitrogen bearing molecule $\mathrm{NH}_{4}{ }^{+}$we can estimate its column density. Using the integrated band strength of $\mathrm{NH}_{4}{ }^{+}$ ( $\left(\mathrm{II} a ; \mathrm{G} 89 b\right.$ ) we calculate a corresponding $\mathrm{NH}_{4}{ }^{+}$column density in $\mathrm{W} 33 \mathrm{~A} \sim 7 \times 10^{17} \mathrm{~cm}^{-2}$. This gives a reasonable ratio of $\sim 2 \%$ relative to $\mathrm{H}_{2} \mathrm{O}$ (Tielens et al. 1984). Within the uncertainty of about a factor of 2 involved in such calculations (G89b), the fractional abundance of $\mathrm{NH}_{4}{ }^{+}$when considered as a counterion to $\mathrm{OCN}^{-}$is consistent with the estimated $\left[\mathrm{OCN}^{-}\right] /\left[\mathrm{H}_{2} \mathrm{O}\right]=1 \%$ in W33A (GG87). From the strength 
$\therefore$ of the shoulder at $6.3 \mu \mathrm{m}$ we estimate the fractional $\mathrm{HCOO}^{-}$ abundance to be less than $1 \%$ relative to $\mathrm{H}_{2} \mathrm{O}$ in the line of , sight towards W33A.

Finally, the comparisons shown in Figure $1 b$ and $1 c$ can lead to the following suggestion for line-of-sight effects: (i) Figure $1 b$ and the $5-8 \mu \mathrm{m}$ spectral region of W33A imply grains with photolyzed and slightly annealed ice mantles accounting for the $6 \mu \mathrm{m}$ band. The temperature is such that $\mathrm{H}_{2} \mathrm{O}$ sublimation has not occurred over astrophysical time scales, so that the dust temperature is probably less than $100 \mathrm{~K}$. As can be seen from Figure $1 b$ these grains will contribute little to the $6.86 \mu \mathrm{m}$ band. (ii) Figure 1c suggests that in order to account for the $6.86 \mu \mathrm{m}$ absorption in W33A one requires mantles on grains which are closer to the protostellar source and which therefore have elevated temperatures. Actually a continuum of grain mantle compositions between types (i) and (ii) should be used to account for the 5-8 $\mu \mathrm{m}$ spectrum.

\section{d) Contribution of the 6.86 Micron Band Carrier to the 3.0 Micron Band of $W 33 A$}

In the $\mathrm{H}_{2} \mathrm{O} / \mathrm{NH}_{3} / \mathrm{CO} / \mathrm{O}_{2}$ photolysis experiments (G89b) simultaneously with the formation of the $6.86 \mu \mathrm{m}$ band, a broad band ranging from 3 to $4 \mu \mathrm{m}\left(3300-2500 \mathrm{~cm}^{-1}\right)$ grew in (measured by difference spectra) which was attributed to $\mathrm{N}-\mathrm{H}$ (and $\mathrm{C}-\mathrm{H} / \mathrm{O}-\mathrm{H}$ ) stretches. Of course, the presence of this band must not violate the observations. To verify this we made a comparison with the observational data in the $3 \mu \mathrm{m}$ region. In Figure 2 the overall spectrum of W33A is compared with a composite spectrum of two laboratory IR spectra of the irradiated $\mathrm{H}_{2} \mathrm{O} / \mathrm{NH}_{3} / \mathrm{CO} / \mathrm{O}_{2}=10 / 1 / 1$ mixture: one is taken at $12 \mathrm{~K}$ after the simultaneous irradiation and deposition while the other one is taken after $20 \mathrm{hr}$ annealing at $176 \mathrm{~K}$. The comparison was made with the observations of W33A by Soifer et al. (1979), while the continuum of W33A was taken from Baas et al. (1988). The depths of the 6.0 and $6.86 \mu \mathrm{m}$ bands are reproduced; the fit in the $3 \mu \mathrm{m}$ region is not superb but shows a reasonable agreement. We must point out that trying to match

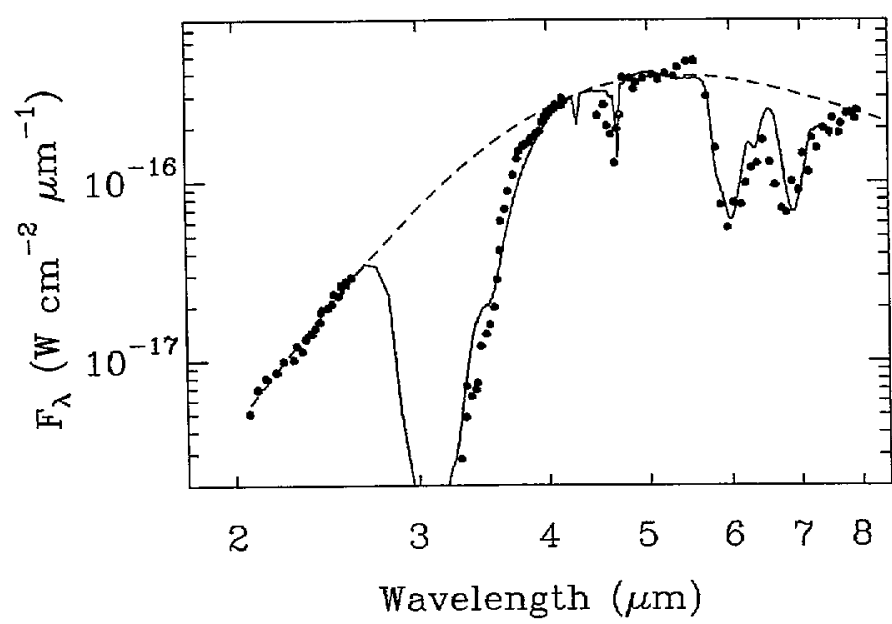

FIG. 2.-The original 2-8 $\mu \mathrm{m}$ spectrum of W33A (Soifer et al. 1979) compared with a composite spectrum of irradiated $\mathrm{H}_{2} \mathrm{O} / \mathrm{NH}_{3} / \mathrm{CO} / \mathrm{O}_{2}=10 / 1 / 1 / 1$. The IR spectrum taken after $20 \mathrm{hr}$ annealing time at $176 \mathrm{~K}$ was multiplied by a factor of 12 and added to the IR spectrum taken after simultaneous irradiation and deposition at $12 \mathrm{~K}$. The resolution is $4 \mathrm{~cm}^{-1}$. The continuum is taken from Fig. 2 in Baas et al. (1988). material (laboratory) absorption spectra to astronomical spectra in the $3 \mu \mathrm{m}$ region requires proper consideration of grain sizes and shapes (Greenberg 1972; van de Bult, Greenberg, and Whittet 1985) which are not included here, so that comparisons as presented in Figure 2 should be taken only as an indication.

\section{e) Other Protostellar Spectra}

The degree of the variability of the band position $(\sim 0.05$ $\mu \mathrm{m}$ ) and shape of the " 6.86 " $\mu \mathrm{m}$ feature in the variously photoprocessed and heated grain mantle analog mixtures (G89b) is consistent with the kind of the variability observed in the dust around such protostellar sources as W33A, GL 2136, W3/IRS 5 , and NGC 7538/IRS 9, where the peak position of the " 6.86 " $\mu \mathrm{m}$ feature in these objects varies from 6.83 to $6.86 \mu \mathrm{m}$ (Tielens and Allamandola 1987; note also that the resolution of these observations was only $\lambda / \Delta \lambda \sim 50$ ). In order to discuss properly small variations, one needs observations with a better resolution than are currently available in the literature.

The varying broadness and relative strength of the " 6.8 " $\mu \mathrm{m}$ feature in GL 961, NGC 2024/IRS 2 and Mon R2/IRS 2 is not yet understood and requires further experimental study.

\section{CONCLUSIONS}

Evidence for photoprocessing and heating of interstellar grain mantles (Lacy et al. 1984; Geballe et al. 1985; dH86; GG87; Schutte 1988; G89b) has already been used to interpret several infrared features observed towards W33A. We have demonstrated here that similar processing is also capable of reproducing the $6.86 \mu \mathrm{m}$ absorption band. Laboratory simulation experiments (G89b) suggest that $\mathrm{NH}_{4}{ }^{+}$is an attractive candidate to account for the $6.86 \mu \mathrm{m}$ absorption.

Magnesium carbonates and $\mathrm{Mg}$-rich hydrated silicates (Hecht et al. 1986) in the cores of the core-mantle dust particles are not excluded from contributing to the $6.86 \mu \mathrm{m}$ absorption, but the fact that W33A shows independent evidence for photoprocessed annealed ice mantles makes it very likely that $\mathrm{NH}_{4}{ }^{+}$ is a major contributor to the $6.86 \mu \mathrm{m}$ band. The observed strength of the $3.53 \mu \mathrm{m}$ absorption limits the maximum contribution by $\mathrm{CH}_{3} \mathrm{OH}$ to the $6.86 \mu \mathrm{m}$ band to $10 \%$ (Baas et al. 1988; G89a).

The 5-8 $\mu \mathrm{m}$ spectrum of W33A indicates a continuum of mantle compositions. Photolyzed and somewhat annealed ice mantles account for the $6.0 \mu \mathrm{m}$ absorption band in W33A, while the position and width of the $6.86 \mu \mathrm{m}$ feature indicate the presence of warmer photolyzed dust mantles, which have lost their $\mathrm{H}_{2} \mathrm{O}$ leaving a more refractory mantle material. The scaling of the temperatures observed in the laboratory to the interstellar case is not straightforward as a result of the longer time scales in a molecular cloud. A rough estimate gives dust temperatures below $100 \mathrm{~K}$ to account for the observed $\mathrm{H}_{2} \mathrm{O}$ bands, whereas the dust mantles closer to the protostellar source may have exceeded this value, thus accounting for the observed $6.86 \mu \mathrm{m}$ absorption.

Clearly, more work on the analysis of the protostellar spectra has to be done. Higher resolution spectra of the $5-8 \mu \mathrm{m}$ spectral region of protostars taken with ISO will reveal further details, such as accurate band positions and the presence of an absorption at $6.3 \mu \mathrm{m}$ which is clearly seen in the laboratory spectra taken at $4 \mathrm{~cm}^{-1}$ resolution. 
Baas, F Grim, R. J A Geballe, T. R Schutte, W A, and Greenberg J M. 1988 , in Dust in the Universe, ed. M. E. Bailey and D. A. Williams (Cambridge: Cambridge University Press), p. 55.

d'Hendecourt, L. B., Allamandola, L. J., Grim, R. J. A., and Greenberg, J. M. 1986, Astr. Ap., 158, 119 (dH86).

- Geballe, T. R., Baas, F., Greenberg, J. M., and Schutte, W. 1985, Astr. Ap., 146, L6.

Greenberg, J. M. 1972, J. Colloid Interface Sci., 39, 513. 1982 , in Submillimetre Wave Astronomy, ed. J. E. Beckman and J. P. Phillips (Cambridge: Cambridge University Press), p. 261.

Grim, R. J. A., Geballe, T. R., Baas, F., and Greenberg, J. M. 1989a, Astr. Ap. Letters, submitted (G89a).

Grim, R. J. A., and Greenberg, J. M. 1987, Ap. J. (Letters), 321, L91 (GG87).

Grim, R. J. A., Schutte, W. A., Greenberg, J. M., Baas, F., and Schmitt, B. $1989 b$, Astr. Ap. Suppl., in press (G89b).

Hecht, J. H., Russell, R. W., Stephens, J. R., and Grieve, P. R. 1986, Ap. J., 309 , 90

Knacke, R. F., and Krätschmer, W. 1980, Astr. Ap., 92, 281.
Lacy, J. H., Baas, F., Allamandola, L. J., Persson, S. E., McGregor, P. J., Lonsdale, C. J., Geballe, T. R., and van de Bult, C. E. P. M. 1984, Ap. J., 276,

Larson, H. P., Davis, D. S., Black, J. H., and Fink, U. 1985, Ap. J., $299,873$.

Puetter, R. C., Russell, R. W., Soifer, B. T., and Willner, S. P. 1979, Ap. J., 228 118 (P79)

Russell, R. W., Soifer, B. T., and Puetter, R. C. 1977, Astr. Ap., 54, 959.

Sandford, S. C., and Walker, R. M. 1985, Ap. J., 291, 838.

Schutte, W. A. 1988, Ph.D. thesis, University of Leiden.

Soifer, B. T., Puetter, R. C., Russell, R. W., Willner, S. P., Harvey, P. M., and Gillett, F. C. 1979, Ap. J. (Letters), 232, L53.

Tielens, A. G. G. M., and Allamandola, L. J. 1987, in Physical Processes in Interstellar Clouds, ed. G. E. Morfill and M. Scoler (Dordrecht: Reidel), p. 333.

Tielens, A. G. G. M., Allamandola, L. J., Bregman, J., Goebel, J., d'Hendecourt, L. B., and Witteborn, F. C. 1984, Ap. J., $287,697$.

van de Bult, C. E. P. M., Greenberg, J. M., and Whittet, D. C. B. 1985, M.N.R.A.S., 214, 289.

RuUd J. A. Grim and J. MAYo GreEnBerg: Laboratory Astrophysics, Huygens Laboratory, University of Leiden, P.O. Box 9504, 2300 RA, Leiden, The Netherlands

Willem A. SchutTe: NASA/Ames Research Center, MS 245-6, Moffett Field, CA 94035

BERNARD SCHMitT: Laboratoire de Glaciologie, B.P. 96, 38402, St. Martin d'Hères, France 